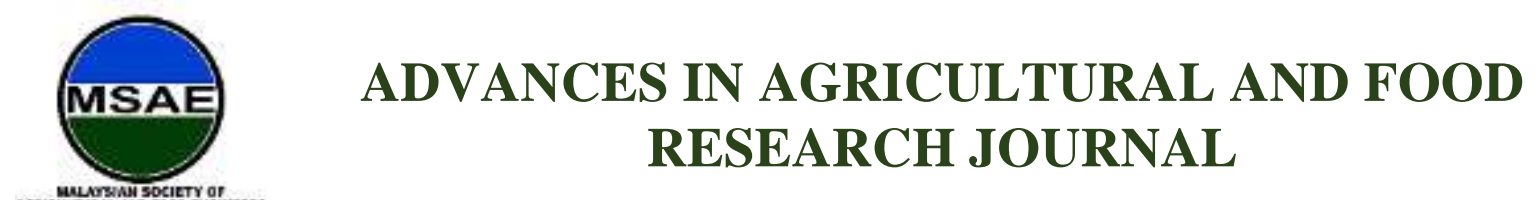

Original Research Article

\title{
Converting Durian-Based Traditional Dessert into Ready-To-Eat Durian Stick through Sausage Technology Application
}

Siti Nurumairah Mohamed Razali ${ }^{1}$, Muhammad Hazwan Hamzah ${ }^{1,2 *}$, Hasfalina Che Man ${ }^{1,2}$, Mohd Zuhair Mohd Nor ${ }^{3,4}$

${ }^{1}$ Department of Biological and Agricultural Engineering, Faculty of Engineering, Universiti Putra Malaysia, 43400 UPM Serdang, Selangor, Malaysia,nurumairah505@gmail.com; hasfalina@upm.edu.my

${ }^{2}$ Smart Farming Technology Research Centre, Faculty of Engineering, Universiti Putra Malaysia, 43400 UPM Serdang, Selangor, Malaysia

${ }^{3}$ Department of Process and Food Engineering, Faculty of Engineering, Universiti Putra Malaysia, 43400 UPM Serdang, Selangor, Malaysia, zuhair@upm.edu.my

${ }^{4}$ Laboratory of Halal Science Research, Halal Products Research Institute, Universiti Putra Malaysia, 43400 UPM Serdang, Selangor, Malaysia

*Corresponding author: Muhammad Hazwan Hamzah, Department of Biological and Agricultural Engineering; hazwanhamzah@upm.edu.my

Abstract: Durian known as the King of Fruit is a prominent, common native Southeast Asian fruit and very popular among the local Malaysians. Nowadays, there are various types of durian-based products available in the market such as ice-cream, cakes, chips, chocolate bars, and pre-mixed powders. There are also traditional dessert products produced using fresh durian filling such as 'dodol', 'lempuk' and 'bingka'. However, as time goes on, traditional desserts are increasingly forgotten. The aim of this study was to diversify durian-based products into Ready-To-Eat (RTE) durian stick. The stick production technique began with the process of grinding the durian paste, mixing the ingredients, stuffing the mixture into the sausage casing, steaming the mixture and chilling the RTE durian stick. Next, the firmness and moisture content of the RTE durian stick production were also analyzed. Apart from that, sensory evaluation is conducted to determine the consumer acceptance of the RTE durian stick that has been produced. Based on the results obtained, the best firmness for this RTE durian stick is $10.42 \mathrm{~N}$. The value of the moisture content obtained is high, which is between $52.05 \%$ to $61.89 \%$. The overall acceptability of RTE durian stick resulted 3.7 out of its full score which is 5. For the RTE durian stick, where the RTE durian stick was satisfactory to the panellists, the overall acceptability showed a score of $74 \%$. In conclusion, this method can be used to increase the added value and uniqueness of the RTE durian-based stick produced, however, improvements such as product formulations and freezing methods to extend the product's shelf life is necessary for the future to produce better RTE dessert products. The RTE durian stick has potential to be commercialized for local and international markets based on the overall acceptability in terms of the texture, appearance, smell and taste.

Keywords: durian; dessert; traditional; sausage; technology 
Received: $16^{\text {th }}$ December 2020

Received in revised form: $15^{\text {th }}$ February 2021

Citation: Mohamed Razali SN, Hamzah MH, Che Man H, et al. (2021). Converting durian-based traditional dessert into ready-to-eat durian stick through sausage technology application. Adv Agri Food Res J 2021; 2(1): a0000198.

Available Online: $1^{\text {st }}$ April 2021

\section{Introduction}

Durian known as the King of Fruit is a famous and popular native fruit of Southeast Asia (Ho \& Bhat, 2015). It is a seasonal fruit that is usually found and harvested from June to August yearly (Tan et al., 2019). In Malaysia, durian has been declared as a new catalyst for the growth of the country's economy. Nowadays, the durian tree can be found to be planted everywhere around the country. The nutritional value contained in durian also makes it one of the reasons why durians are so popular. Arancibia-Avila et al. (2008) stated that durian contained high antioxidants and it differs for each stage of maturity. There is a high demand for fresh durians domestically and internationally. Malaysia is the second-largest producer and exporter of durian, in which Thailand is the main producer of durian in Asia. Durian is commonly consumed fresh by eating the flesh of the fruit. Other than that, there is a lot of durian dessert and durian-based product that are available in Malaysia. Some of the examples of durian dessert are namely 'dodol', durian ice-cream, durian-flavored sticky rice in coconut milk, durian 'cendol' and durian crepe. The example of durian-based products are durian chocolate, durian premix coffee and durian popcorn. There are some durian pastes made from fermented durian flesh such as 'tempoyak' which is cooked with fresh fish, prepared into a spicy dressing or sauce to be dipped with fresh vegetables or Malaysian salad known as 'ulam', whereas 'lempuk', durian flesh leftover is pre-cooked with sugar or brown sugar and used as a flavoring for sweet porridge or spread on the bread.

However, most of the durian desserts are not available in a ready-to-eat dessert (RTE). RTE food is food that has been prepared and it can be consumed as is, without any additional cooking. RTE foods can be refrigerated, shelf-stable, require minimal heating, or are served hot. Dudeja and Singh (2016) reported that nowadays, people preferred easy and short ways of cooking food rather than spending too much time in elaborate cooking due to their hectic lifestyle. The production of various new desserts causes the durian-based traditional dessert is being forgotten as manufacturers and entrepreneurs are focusing on the production of modern dessert. This is due to the fusion-modern desserts require less-time consumption for cooking compared to the preparation time for traditional desserts. Besides, the development of RTE durian-based dessert by using modern technologies is still limited in Malaysia. This is because the shelf life of fresh durians is limited to a week; whereas the rotten durians only last for two to three days (McMahon, 2003).

Malaysia's food processing sector undergoes a fast-developing state as there are nearly more than 8,000 companies, mostly consist of Malaysian's small and medium-sized enterprises. For example, Saudee Group Berhad, Ramly Food Processing Sdn. Bhd. and 
Ayamas Food Corporation Sdn. Bhd. are famous food processing companies in Malaysia. These companies are specialized in the production of sausages. Frankfurters are common sausage type products available in the commercial market in Malaysia and other sausagetype products are only available as part of the menu at the international hotels and restaurants in the city (Nurul et al., 2010). She also reported that more advanced technologies have been imported from other countries due to the competition between manufacturers to produce high-quality products.

Within the sausage production concept, an area of research that has gained significant interest is the development of other types of RTE food by using sausage technology. Traditional sausages are raw meat-based products, such as lamb, beef, pork, mutton and poultry, which has been cured or salted for preservation purposes due to its high perishability. There are four categories of sausage: (1) fresh sausage; (2) cooked sausage; (3) semi-dry and dry sausage; (4) specialty meats. It can be further broken down into different types such as fresh sausage, fermented sausage, smoked processed sausage, emulsion sausage and cooked sausage (Abdolghafour \& Saghir, 2014). Traditionally, fermented meat sausages were considered healthy and safe foods, however, eating them may cause several health hazards caused by the contents of saturated fats and $\mathrm{NaCl}$, presence of nitrite and degradation products such as nitrosamines and PAHs (Askild et al. 2017). Abdolghafour and Saghir (2014) have done a critical review on the development of sausage production practices and effects of incorporation of the different non-meat ingredients such as milk, soy protein, potato starches, egg white, sago flour and vegetable protein into the meat product that improve the quality attributes and functional properties. Therefore, venturing into alternatives to meat sausages for a balanced healthy diet, several researches have been conducted to introduce vegetable-based and fruit-based sausages, whereby Burri et al. (2011) have developed sausages made out of carrot $(50 \% \mathrm{w} / \mathrm{w})$, sugar beet $(50 \% \mathrm{w} / \mathrm{w})$ and tomato $(40 \% \mathrm{w} / \mathrm{w})$, with tofu $(20 \% \mathrm{w} / \mathrm{w})$ and $0.8 \%(\mathrm{w} / \mathrm{w})$ of seaweed to meet the younger consumer demands that are intolerant to some animal proteins. Furthermore, it is to promote consumption of fruits and vegetables through these vegetables and fruit sausages. These sausages can also be marketable to the vegetarian and vegan communities which do not consume any meat or meat-products due to religious or health belief. As in this research, we are promoting the incorporation of durian into our fruit-based stick to turn it into a nice dessert and ready-toeat snack, compared to those home-made fruit-based sausages known as dried fruit sausage (i.e. made from apple, pepper and olive) (Ellen, 2021).

Preceding research has successfully demonstrated the use of sausage technology by the dessert based on the 'bingka pisang' recipe using overripe bananas for the suitability of the process (Hasnim \& Nor, 2018). A greater amount of banana in the formulation resulted in a sample with a smoother texture, a higher moisture content and a darker colour. The presensory evaluation of the 'bingka pisang' exhibited that formulation with greater amount of banana was more acceptable compared to other sample. It seems promising to transform the 
conventional local banana-based dessert to become RTE food, but more explorations are needed to enhance the product for the acceptance and commercialization purpose.

All processes involved in the production of sausage were used to produce the samples. The purpose of adopting sausage technology is to increase the added value of the samples. For instance, the stuffing process added uniqueness to the RTE durian stick. Apart from its unique shape, the usage of casing can prevent the surface of the RTE durian stick from being contaminated, whereas traditionally, the surface of the durian-based dessert is exposed to the environment as it needed to be cut before being served.

Traditionally, the durian-based dessert is baked for one hour (Nur, 2019). However, by adopting the sausage technology, the cooking process and time of the durian-based dessert has been shortened through the steaming process. Steaming seems healthier than the baking method. This is because before the mixture was placed into the oven, the container should be smeared with oil to prevent the dessert from sticking to the flat surface. Besides, baking required more energy compared to steaming. According to Le-bail et al. (2010), baking is concerned by energy demand as it is estimated that baking demands two to five times more energy than any other food processing.

Therefore, the main objective of this study is to diversify durian-based products into RTE durian stick. The specific objectives are (1) to develop a process design for the production of RTE durian stick (2) to determine the effect of RTE durian stick formulation of the physicochemical properties (3) to determine the acceptability of RTE durian stick through sensory analysis.

\section{Materials and Methods}

\subsection{Sample Preparation}

The variety of durian paste used for sample preparation was D24. The D24 durian paste was purchased from Makatas Industries Sdn. Bhd. Coconut milk, coarse grain sugar and fine salt were acquired from sundry shop in Serdang.

The recipe for this durian traditional dessert was adapted with some modifications (MyResipi, 2012). Apart from the different amounts of flour and durian paste, the number of other ingredients such as sugars, salt and coconut milk were modified in order to obtain the optimized firmness from Response Surface Methodology (RSM) (Section 2.2). The modified amount of ingredients is provided in Table 1. 
Table 1. The modified amount of ingredients used

\begin{tabular}{cc}
\hline Ingredients & $\begin{array}{c}\text { Amount } \\
\text { (grams) }\end{array}$ \\
\hline Flour & $15-25$ \\
Durian paste & $5-15$ \\
Coconut \\
milk & 46 \\
$\begin{array}{c}\text { Coarse grain } \\
\text { sugar } \\
\text { Salt }\end{array}$ & 10 \\
\hline
\end{tabular}

\subsubsection{Grinding}

The durian was filled into a hand crank manual meat grinder (MLY-663, MEILEYI, China) and ground to produce a finer texture. The finer grind setting is to ensure the frozen seedless pulp becomes durian puree. It is easy to mix the durian puree with other ingredients such as flour, coarse grain sugar, fine salt and coconut milk.

\subsubsection{Mixing}

The flavor and texture of the dessert produced were dependent on this process. For the process, a hand mixer (HM300, KHIND, Malaysia) was used. Fine salt and sugar were added into the durian puree and mixed well. Then, flour was added along with coconut milk and the mixture was mixed. The process was repeated until all ingredients were added. During the mixing process, the temperature was maintained at room temperature, between $27^{\circ} \mathrm{C}$ to $29^{\circ} \mathrm{C}$.

\subsubsection{Stuffing}

The casing used for this study is the cellulose-based casing, which is artificial and inedible. The diameter of the casing is $2.5 \mathrm{~cm}$ and the length used is $18 \mathrm{~cm}$ per stick where 2 $\mathrm{cm}$ from both ends of the tube were used as the area to bind both ends of the casings by using string. The casing was slipped onto the stuffing horn that was attached to the stick stuffer (MLY-663, MEILEYI, China). The durian stick mixture was filled into the sausage stuffer and the mixture started to fill the casing. The process stopped when it reached about $2 \mathrm{~cm}$ from the end of the stick casing. Both ends of the stick were tied as closely as it can to prevent air pockets in the stick (Figure 1).

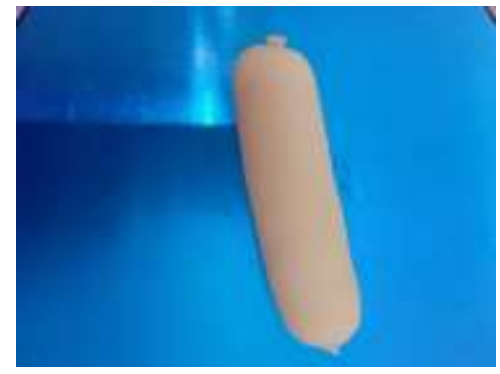

Figure 1. Ready-to-eat durian stick. 


\subsubsection{Steaming}

The steaming process was chosen as the method to cook the sticks. The sticks were steamed by using an electric steamer (PSM-162S, PENSONIC, Malaysia) at $100^{\circ} \mathrm{C}$ for 30 minutes to preserve the product by removed the remaining microbes and changed the texture for the slurry to solid.

\subsubsection{Chilling}

The cooked sticks were immersed in a cooling water bath and it was left to rest. The temperature of the cooling water bath is below $4{ }^{\circ} \mathrm{C}$ and it is left to rest for 5 minutes before the casings were removed. The purposes of immerging sticks into a cooling water bath are to facilitate the removal of sticks casings, maintaining its shape and prevent shrinkage of the sticks.

\subsubsection{Freezing}

The durian sticks were packed into the food zipper bag and sealed. The packed products were placed in a freezer at $4^{\circ} \mathrm{C}$ to preserve them and longing the shelf life of the produced RTE durian sticks produced.

\subsection{Optimization using RSM}

The RSM analysis was conducted using Design Expert (Version 11, StatEase, Minneapolis). Two parameters were chosen, the amount of flour and the amount of durian paste, and keyed into the software, as shown in Table 2. Both parameters are defined by the system as gram.

Table 2. The numerical factors.

\begin{tabular}{cccccc}
\hline Factor & Name & Units & Type & Minimum & Maximum \\
\hline A & $\begin{array}{c}\text { Amount of } \\
\text { flour } \\
\text { Amount of } \\
\text { durian paste }\end{array}$ & Gram (g) & Numeric & 15 & 25 \\
B & Gram (g) & Numeric & 5 & 15 \\
\hline
\end{tabular}

A central composite design (CCD) was prepared for the 12 random experiments to generate a response surface which determine the optimal value of $\mathrm{A}$ and $\mathrm{B}$ factors and produce the highest response variable, as shown in Table 4.

The firmness obtained was keyed in using the software and the optimization process started. For optimization of the data, the software was set up to generate both the targeted amount of flour and durian paste that result in the optimum firmness. The chosen optimized data with the highest desirability was tested by carrying out another experiment to confirm the firmness. Table 3 shows the set-up criteria. 
Table 3. Independent variables and the level of central composite design (CCD).

\begin{tabular}{|c|c|c|c|c|}
\hline \multirow{2}{*}{ Factors } & \multirow{2}{*}{ Parameters } & \multicolumn{2}{|c|}{ Limit } & \multirow{2}{*}{ Criteria } \\
\hline & & Lower & Upper & \\
\hline A & $\begin{array}{l}\text { Amount of flour } \\
(\mathrm{g})\end{array}$ & 15 & 25 & Target \\
\hline B & $\begin{array}{c}\text { Amount of } \\
\text { durian paste }(\mathrm{g})\end{array}$ & 5 & 15 & Target \\
\hline $\mathrm{Y}$ & Firmness (N) & 4.5 & 20 & Maximum \\
\hline
\end{tabular}

\subsection{Statistical Analysis}

The results of CCD were analyzed using Minitab (Version 16.1). Analysis of Variance (ANOVA) and regression along the predicted have been evaluated. In the quadratic equation, the firmness surface was expressed as defined in Equation 1.

$$
\mathrm{Y}=\beta+\mathrm{A}-\mathrm{B}-\mathrm{AB}+\mathrm{A}^{2}+\mathrm{B}^{2}
$$

Where $\mathrm{Y}$ is the predicted response, $\beta$ is the intercept, $\mathrm{A}$ and $\mathrm{B}$ are both denote for the factor variables which is the amount of flour and durian paste, respectively.

\subsection{Analysis of RTE Durian Stick}

\subsubsection{Compression Analysis}

The chilled stick was maintained at room temperature for two hours before analysis. The gels were sliced into a cylinder (25 $\mathrm{mm}$ diameter and $25 \mathrm{~mm}$ length). The hardness test was performed using a compression tester, Instron Universal Testing Machine (Instron, USA) equipped with a maximum $20 \mathrm{~N}$ load cell. The sample was placed on a heavy-duty platform and force was applied. The forces were applied to the sample by using a compression probe to determine the maximum load cell that the stick can hold until the breakpoint using a crosshead speed of $20 \mathrm{~cm} \mathrm{~min}^{-1}$. The hardness measurements were performed in triplicate and the results were averaged. The readings are expressed in the unit of Newton $(\mathrm{N})$.

\subsubsection{Moisture Content}

The moisture content of the samples was measured by using a moisture analyzer (MX-50 Moisture analyzer, Japan) after 2 hours of defrosting process following the method described by Hasnim and Nor (2018). The moisture content value can be calculated by measuring the initial weight of the stick sample and subtract it with the final weight of the 
sample after being heated at $105^{\circ} \mathrm{C}$ until the weight becomes constant. The sample weight used in this experiment was 8.0 grams.

\subsubsection{Sensory Analysis}

In sensory terms, the acceptability of food is affected by the inherent properties it possesses, that is, the food's aroma, smell, texture, flavor, auditory attributes, and aftertaste (Murray \& Baxter, 2003). The chosen optimized data with the highest desirability was tested for sensory analysis (20.44 grams of flour with 10 grams of durian paste). 20 random participants (both male and female, bachelor students) are chosen to test and evaluate the sensory properties of the samples. Samples were served and evaluated at service temperature. The samples were re-steamed for 30 minutes until cooked and the samples were cut into cylindrical shapes of $25 \mathrm{~mm}$ diameter and $25 \mathrm{~mm}$ length. All samples were displayed to every tester on a plastic plate. Each of the participants was given an assessment sheet to evaluate five attributes of the samples, which are appearance, aroma, texture, flavor and overall acceptability based on the five-point hedonic scale $(1=$ disliked extremely and $5=$ liked extremely).

\section{Results and Discussion}

\subsection{Optimisation of Amount of Flour and Durian Paste by using RSM}

\subsubsection{RSM experimental design}

RSM was used to optimise the amount of flour and durian paste for the production of RTE durian stick. A central composite design (CCD) results in Table 4 shows the optimization of process variables with firmness factorial in 12 experiment runs. Generally, the formulation of a high amount of flour produced the highest firmness. Based on Table 4, with a 25 grams amount of flour, and 5 grams of durian paste, the firmness obtained was $20.07 \mathrm{~N}$. This is because the flour contains gluten. Gluten is a protein that functions as an extending and binding agent and is widely used as an additive for improved texture, moisture retention, and flavoring in processed foods (Biesiekierski, 2017).

Table 4. List of experiment runs for RTE durian stick.

\begin{tabular}{cccc}
\hline & Factor 1 & Factor 2 & Response \\
\cline { 2 - 4 } Run & A: Flour $(\mathbf{g})$ & $\begin{array}{c}\text { B: Durian paste } \\
(\mathbf{g})\end{array}$ & Firmness $(\mathbf{N})$ \\
\hline 1 & 20 & 10 & 9.89 \\
2 & 20 & 5 & 11.58 \\
3 & 25 & 5 & 20.07 \\
4 & 15 & 15 & 4.52 \\
5 & 25 & 15 & 16.03 \\
6 & 20 & 15 & 8.94 \\
7 & 20 & 10 & 9.83 \\
8 & 15 & 10 & 5.29 \\
9 & 20 & 10 & 9.82 \\
\hline
\end{tabular}




\begin{tabular}{cccc}
\hline \multirow{2}{*}{ Run } & Factor 1 & Factor 2 & Response \\
\cline { 2 - 4 } & A: Flour $(\mathbf{g})$ & $\begin{array}{c}\text { B: Durian paste } \\
(\mathbf{g})\end{array}$ & Firmness $(\mathbf{N})$ \\
\hline 10 & 15 & 5 & 6.63 \\
11 & 25 & 10 & 17.53 \\
12 & 20 & 10 & 9.96 \\
\hline
\end{tabular}

Figure 2 shows the 3D surface plot for the firmness of RTE durian stick. The surface plot produced by RSM presents the relationship between the independent and experimental data variables. The red dots in Figure 2(a) indicates the values that exceed the expected value, while the pink dots represent the value below the expected value. According to Figure 2, the surface slot shows that amount of flour and the amount of durian paste used were ideally related to the firmness. Figure 2(a) showed that the highest point on the 3D plot is below the expected value, hence an optimization was carried out and resulted in a more uniform 3D plot as shown in Figure 2(b). The optimized response surface plot as shown in Figure 2(b) revealed the increased firmness with increasing amount of durian paste and flour added. There was a total of 12 solutions generated following the criteria set up, where only solution with the highest desirability to achieve the criteria will be chosen to carry out a confirmation test on firmness. The chosen criteria with 0.702 desirability was $20.44 \mathrm{~g}$ of flour and the 10 $\mathrm{g}$ of durian paste. Based on the confirmation test, the firmness was $10.42 \mathrm{~N}$. The optimized condition of confirmation test was chosen for further sensory analysis.

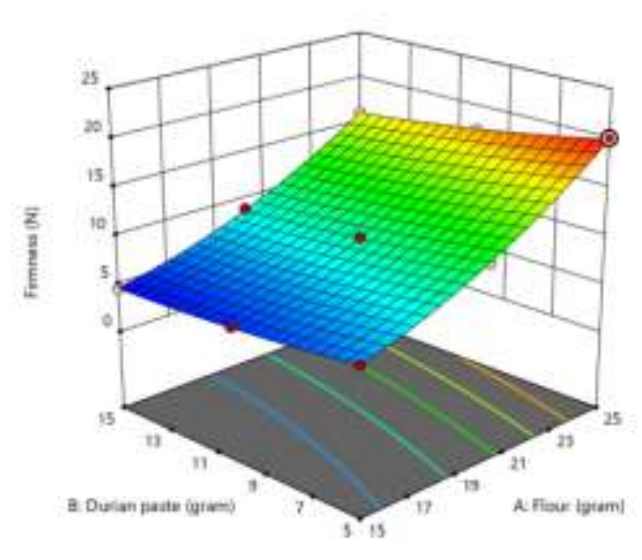

(a)

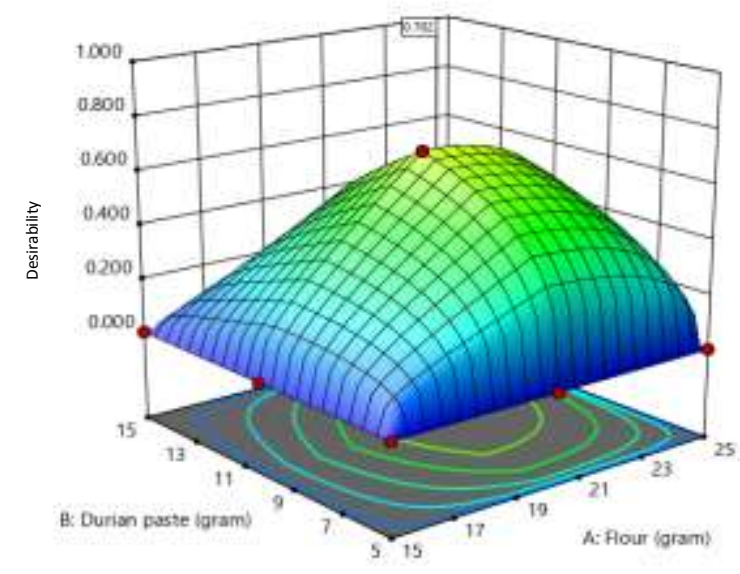

(b)

Figure 2. 3D response surface plot (a) response surface plot before optimization; (b) response surface plot after optimization.

\subsubsection{Model Fitting and Statistical Analysis}

A validation check was conducted to validate the process design and the ANOVA test resulted for firmness as presented in Table 5. Table 5 shows that the model F-value of 3193.37 implies the model is significant. A $0.01 \%$ possibility that the large F-value may due to noise. $\mathrm{P}$-values less than 0.05 indicate model terms are significant. In this case, $\mathrm{A}, \mathrm{B}, \mathrm{AB}$, $\mathrm{A}^{2}, \mathrm{~B}^{2}$ are significant model terms as the P-values are below 0.1 . The lack of a Fit F-value of 
6.81 implies that there is a $7.48 \%$ possibility that the large value may also occur due to noise. Since the percentage errors are less than $10 \%$, therefore, the response model has a valid prediction (Faridah \& Aziah, 2012). Fit statistical analysis for the experimental is where $R^{2}$ is the statistical measurement to measure the accuracy of the fitted regression line. The predicted $R^{2}$ of 0.997 is in reasonable agreement with the adjusted $R^{2}$ of 0.9993 where the difference is less than 0.2. -Adequate Precision measures the signal to noise ratio. A ratio greater than 4 is desirable. The ratio of 172.13 indicates an adequate signal.

Table 5. The ANOVA and fit statistical analysis.

\begin{tabular}{ccccccc}
\hline Source & Sum of Squares & df & Mean Square & F-value & $\boldsymbol{p}$-value & \\
\hline Model & 253.09 & 5 & 50.62 & 3193.37 & $<0.0001$ & significant \\
A-Flour & 230.41 & 1 & 230.41 & 14536.24 & $<0.0001$ & \\
B-Durian paste & 12.88 & 1 & 12.88 & 812.65 & $<0.0001$ & \\
AB & 0.9331 & 1 & 0.9331 & 58.87 & 0.0003 & \\
A $^{2}$ & 6.38 & 1 & 6.38 & 402.60 & $<0.0001$ & \\
B $^{2}$ & 0.4132 & 1 & 0.4132 & 26.07 & 0.0022 & \\
Residual & 0.0951 & 6 & 0.0159 & & & \\
Lack of Fit & 0.0829 & 3 & 0.0276 & 6.81 & 0.0748 & not significant \\
Pure Error & 0.0122 & 3 & 0.0041 & & & \\
Cor Total & 253.18 & 11 & & & & \\
Std Dev & 0.1259 & \multicolumn{7}{c}{ Adjusted $R^{2}$} & 0.9993 & & \\
Mean & 10.84 & \multicolumn{7}{c}{ Predicted $R^{2}$} & 0.9965 & & \\
C. $\% \%$ & 1.16 & Adeq. Precision & 172.1352 & & \\
& & &
\end{tabular}

Figure 3 shows that the firmness of the RTE durian stick in the fitted analytical model is well suited with the observed value that results in a high value of the coefficient of $\mathrm{R}^{2}$ which is 0.99 (Table 5). The colored dots in the graph specify the firmness of durian RTE durian stick. As stated in Figure 3, some colored dots may be below or exceed the expected value. However, Figure 3 had shown the data is proven adequate for the experiment. 


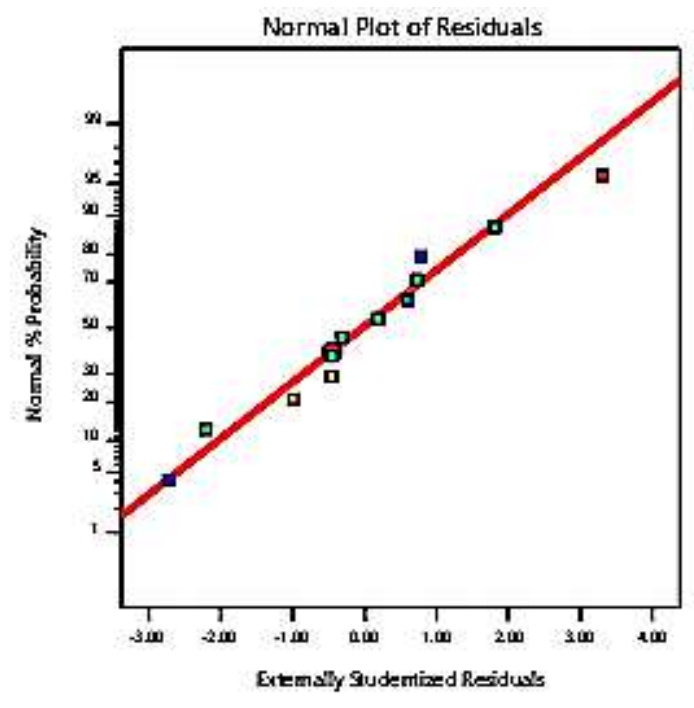

Figure 3. Graph normal plot of residue.

\subsection{Analysis of RTE Durian Stick}

\subsubsection{Compression Analysis}

The RTE durian sticks with different amounts of flour and durian paste have undergone a compression test. The compression test usually reflected the activity of individual jaw, usually as a measurement of how firm the product during the first bite will be (Fellows, 2017). Figure 4 shows the average maximum load for each sample RTE durian stick.

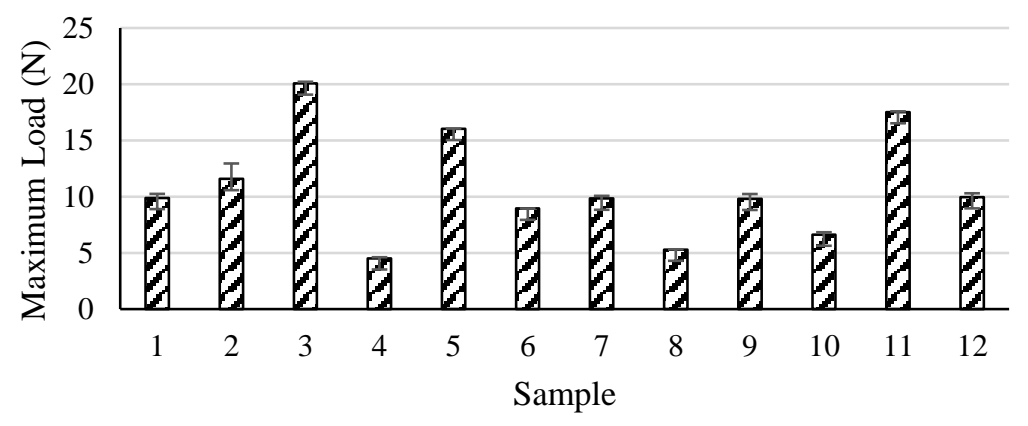

Figure 4. Compression test for each sample.

Based on Figure 4 and Table 4 , the $3^{\text {rd }}$ sample (25 gram of flour and 5 gram of durian paste) has the highest compression load with $20.07 \mathrm{~N}$. This is because the molecules of gluten in the flour are strengthened, when it is heated and this allows the product to hold its shape and produce a firm texture (Alfaro, 2019). The results followed by the $11^{\text {th }}$ sample ( 25 gram of flour and 10 gram of durian paste) with $17.53 \mathrm{~N} .1^{\text {st }}, 7^{\text {th }}, 9^{\text {th }}$, and $12^{\text {th }}$ sample (20 gram of flour and 10 gram of durian paste) shared an average compressive load which is $9.87 \mathrm{~N}$. The $4^{\text {th }}$ sample has the lowest compression load with $4.52 \mathrm{~N}$. This is because the sample has a soft texture in which made from 15 grams of flour and 15 grams of durian paste. As the $4^{\text {th }}$ 
sample contain a high amount of durian paste, the amount of moisture inside the dessert also increases.

The formulation and its interaction between flour and durian paste was complex. The finding can also be explained by the amount of gluten formation in samples. Formation of gluten needs hydration. Less water causes less gluten formation that resulting the proteins to dilute and restricts the interaction. The lesser durian paste content in the sample means the higher starch content that can undergo the gelatinization and retrogradation process during sample preparation and increase the gumminess to the sample (Chisenga et al., 2019; Wang et al., 2015). Retrogradation process affected the sample to have a more compact structure and requires more load to break it.

Freezing can be categorized under refrigerated preservation of food. Refrigeration preservation is the method of preservation to maintain and decrease the temperature of the food materials and thus reduce the food changes rate that cause damages to them. Therefore, freezing and thawing process affects the hardness of the sample. However, the occurrence of crystallization or re-crystallization can adversely affect the characteristics of foods during freezing and thawing processes (Xu et al., 2016). Even though various pre-treatment such as blanching and ohmic heating have been utilized to modify the composition of food, further understanding on the effect of freezing or thawing in terms of temperature, viscoelastic and more need to be investigated in the future.

\subsubsection{Moisture Content}

Moisture content is one of the most important physicochemical features, as it will affect the quality of the stick (Belgis et al., 2016). Figure 5 represents the moisture content in each sample of RTE durian stick. Based on Figure 5, the $3^{\text {rd }}$ sample has the lowest moisture content which is $52.05 \%$, followed by the 11 th sample with $53.9 \%$. 4th sample with the lowest compressive load has the highest moisture content which is $61.89 \%$. The rest of the samples were range from $54.38 \%$ to $61 \%$. However, moisture content for all samples was above $50 \%$. To date, the highest moisture content obtained for 'bingka' is $45.92 \%$ (Murzaini et al., 2020). Apart from other ingredients, the amount of durian paste used also has resulted to an increment in moisture content. Durian has a high moisture content which is in the range of 58.80 to $79.35 \%$ (Charoensiri et al., 2009). High water content in durian cultivars resulted to limited shelf-life of durian fruit. The shelf-life of durian fruit can be extended to seven days, if kept at 5 to 10 degrees Celsius (McMahon, 2003). Moreover, the high moisture content is not suitable for RTE food as moisture content plays an important role in setting appropriate conditions for processing, storing, packaging, and transporting food items (Mauer \& Bradley, 2017). 


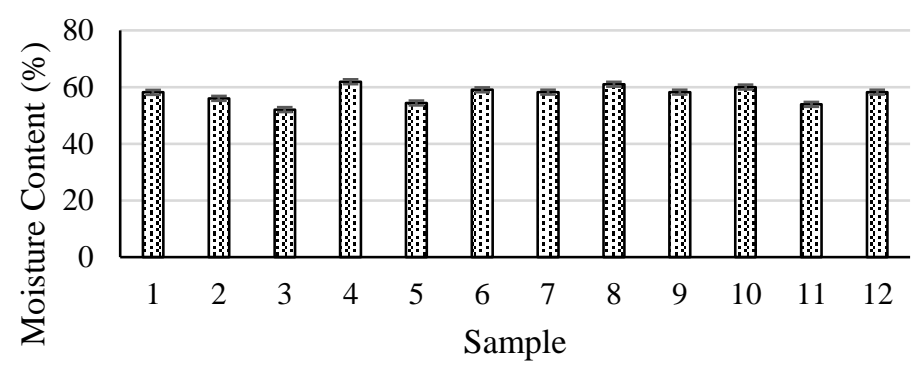

Figure 5. Moisture content for each sample.

\subsubsection{Sensory analysis}

The sensory analysis was conducted for optimized samples of 20.44 grams of flour with 10 grams of durian paste. The results of the sensory analysis of the RTE durian stick samples are presented in Figure 6.

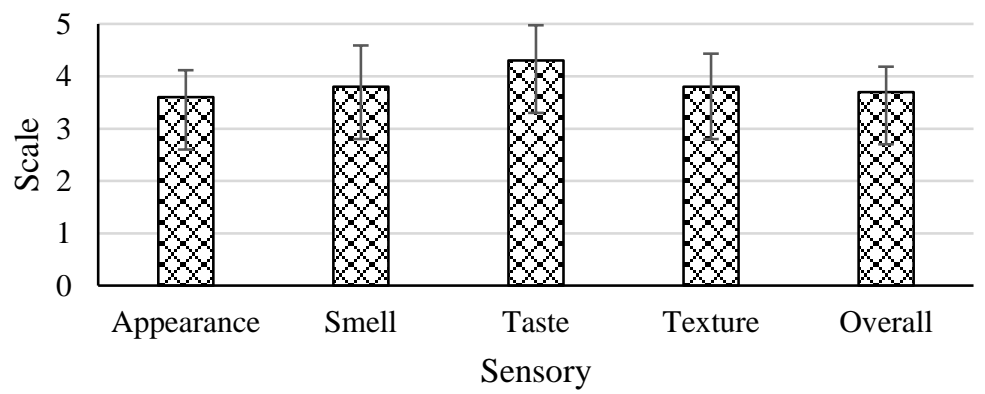

Figure 6. Sensory analysis.

The score of each attribute was an average. Based on the result, the appearance of the sample scored 3.6, whereby six of the panelists moderately like the appearance of the RTE durian stick. Both aroma and texture of the RTE durian stick had scored an average of 3.8 with at least one panelist gave a full score for the RTE durian stick attribute. For the taste of RTE durian stick, most of the panelists gave an average score of 4.3. The taste of RTE durian stick managed to obtain the highest average between the attribute. For overall acceptability, RTE durian stick acquired an average score of 3.7 .

\section{Conclusion}

Overall, this project involves the production of RTE durian stick. This included the development of new formulation through optimization of the amount of flour and durian paste by using RSM to measure the firmness of each formulation and to adapt with a combination of stick technology during the production process. The RTE durian stick produced in this project only uses durian paste and wheat flour as the main ingredient along with coconut milk, salt and sugar. 12 experimental runs were developed. Based on the findings, a lower amount of durian paste (25-gram flour, 5-gram durian paste) in the 
formulation would result in a sample with a harder texture with a lesser moisture content $(52.1 \%)$. Next, the sensory evaluation result was obtained with an overall acceptability average of 3.7 .

As for the recommendation, the formulation of the RTE durian stick can be improvised by adding a preservative to extend the shelf-life of the product. Besides, adding coloring additive to the mixture during the production of RTE durian stick has increased the appearance of the product. Based on the results acquired through this project, converting durian-based traditional desserts to be ready-to-eat food can be a success in the future, however, further research and exploration such as the effect of freezing to prolong the shelflife of the RTE durian stick are required to improvise the product.

Author Contributions: Conceptualization, M.H.H. and M.Z.M.N.; methodology, S.N.M.R.; software, S.N.M.R.; validation, H.C.M. and M.H.H..; formal analysis, S.N.M.R.; investigation, S.N.M.R.; resources, H.C.M. and M.Z.M.N.; data curation, S.N.M.R. and M.H.H.; writing-original draft preparation, S.N.M.R.; writing — review and editing, M.H.H. and H.C.M.

Funding: The authors would like to acknowledge the financial support provided by Department of Biological and Agricultural Engineering, Faculty of Engineering, Universiti Putra Malaysia.

Acknowledgments: Thanks to the Department of Biological and Agricultural Engineering, Department of Food and Process Engineering and Smart Farming Technology Research Centre, Faculty of Engineering, Universiti Putra Malaysia, Selangor, Malaysia.

Conflicts of Interest: The authors declare no conflict of interest.

\section{References}

Abdolghafour, B. \& Saghir, A. (2014). Development in sausage production and practices-A review. Journal of Meat Science and Technology, 2(3), 40-50.

Arancibia-Avila, P., Toledo, F., Park, Y. S., et al. (2008). Antioxidant properties of durian fruit as influenced by ripening. LWT - Food Science and Technology, 41(10), 2118-2125.

Askild, H., Lars, A., Anette, M., et al. (2017). Health and safety considerations of fermented sausages. Journal of Food Quality, 2017, 1-25.

Biesiekierski, J. R. (2017). What is gluten?. Journal of Gastroenterology and Hepatology, 32, 78-81.

Belgis, M., Wijaya, C. H., Apriyantono, A., et al. (2016). Physicochemical differences and sensory profiling of six lai (Durio kutejensis) and four durian (Durio zibethinus) cultivars indigenous Indonesia. International Food Research Journal, 23(4), 1466-1473.

Burri, S., Tato, I., Nunes, M., et al. (2011). Functional vegetable-based sausages for consumption by children. Food and Nutrition Sciences, 2(5): 494 - 501.

Charoensiri, R., Kongkachuichai, R., Suknicom, S., et al. (2009). Beta-carotene, lycopene, and alpha-tocopherol contents of selected Thai fruits. Food Chemistry, 113(1), 202-207.

Chisenga, S. M., Workneh, T. S., Bultosa, G., et al. (2019). Characterization of physicochemical properties of starches from improved cassava varieties grown in Zambia. AIMS Agriculture and Food, 4(4), 939966. 
Dudeja, P., Singh, A. (2016). Safety of Ready-to-Eat Foods. In Dudeja, P., Singh, A. \& Kaur, S. (Eds.), Food Safety Implementation (pp. 429-433). CBS Publishers \& Distributors Pvt Ltd.

Ellen, B. (2021). The Complete Sausage Cookbook: Make Over 300 Kinds of Sausage (pp. 1-484). Cider Mill Press Book Publishers LLC.

Faridah, S., Aziah, N. (2012). Development of reduced calorie chocolate cake with jackfruit seed (Artocarpus heterophyllus Lam.) flour and polydextrose using response surface methodology (RSM). International Food Research Journal, 19(2), 515-519.

Fellows, P. J. (2017). Properties of Food and Principles of Processing. In Fellows, P.J. (Eds.), Food Processing Technology (pp. 3-200). Woodhead Publishing.

Hasnim, H.,j Nor, M. Z. M. (2018). Converting Banana-based Traditional Dessert to a Ready- to-eat Food via Sausage Technology. In H. Che Man, M. H. Hamzah, S. N. A. Mohamad Othman, M. Z. Mohd Nor, \& R. Shamsudin (Eds.), Malaysian Society of Agricultural Engineers Conference Proceedings (pp. 16). Serdang: Malaysian Society of Agricultural Engineers.

Ho, L., Bhat, R. (2015). Exploring the potential nutraceutical values of durian (Durio zibethinus L.) - An exotic tropical fruit. Food Chemistry, 168, 80-89.

Le-bail, A., Dessev, T., Jury, V., et al. (2010). Energy demand for selected bread making processes: Conventional versus part baked frozen technologies. Journal of Food Engineering, 96(4), 510-519.

Mauer, L. J., Bradley, R. L. (2017). Moisture and Total Solids Analysis. In S. S. Nielsen (Ed.), Food Analysis (pp. 257-286). Springer.

McMahon, G. (2003). Fact sheet durians. Northern Territory Government, 1-2.

Murzaini, N. M. N., Taip, F. S., Aziz, N. A., et al. (2020). Effect of pre-treatment in producing pumpkin powder using air fryer and its application in 'Bingka' baking. Current Research in Nutrition and Food Science, $8(1), 48-64$.

MyResipi. (2012). Resepi Bingka Durian Tanpa Telur. Retrieved from https://myresipi.com/recipes/bingkadurian-tanpa-telura

Nur (2019). Resepi Kuih Bingka Durian. Retrieved from https://www.rasa.my/resipi-kuih-bingka-duriansedap-sukatan-bahan-guna-cawan/

Nurul, H., Alistair, T. L. J., Lim, H. W., et al. (2010). Quality characteristics of Malaysian commercial beef frankfurters. International Food Research Journal, 17(2), 469-476.

Tan P. F., Ng S. K., Tan T. B., et al. (2019). Shelf life determination of durian (Durio zibethinus) paste and pulp upon high pressure processing. Food Research, 3(3), 221-230.

Wang, S., Li, C., Copeland, L., et al. (2015). Starch Retrogradation: A Comprehensive Review. Comprehensive Reviews in Food Science and Food Safety, 14(5), 568-585.

Xu, C., Wang, L., Shao, L., et al. (2016). Effect of Freezing/Thawing Temperature on the Viscoelastic and Nutritional Qualities of Carrots. International Journal of Food Properties, 19(6), 1413-1424. 
Copyright $\odot 2021$ by Mohamed Razali, S. N., et al. and HH Publisher. This work is licensed under the 